\title{
Effective Utilization of Mobile Call Center Using Queuing Models
}

\author{
Osahenvemwen O. A. and Odiase O. F.
}

\begin{abstract}
This study presents the effective utilization of mobile call center using queuing models. Aim at achieving effective utilization (management) of queue in service delivery in mobile communication network call center and other relative public infrastructures. Data were obtained from MTN, Globacom, Airtel (Zain) and Estisalat (mobile communication operators) in Nigeria network call centers for a period of one year, and one agent or staff was considered in this analysis. Analytical mathematical models of queue theory were developed, which is based on Markov chain analysis of continuous time and discrete space, are used to model the effective utilization of mobile call center (public infrastructures) based on arrival calls (or rate of subscribers) and service rate. These following parameters were determined which includes; the mean number of customer in service or being served (Ls), the mean number of customer in a waiting queue (Lq), the mean waiting time of customers in the queue (Wq), The mean waiting time of customers in the system (W) (also called sojourn time) and system utilization (p).It is observed that increase in capacity, such as increase in the number of staff (servers) will leads to under utilization of the system, increase in idleness time from the staff. However, if there are low capacities due to low number of staff, it will lead to increase waiting time of the customer.
\end{abstract}

Index Terms-Call arrival center, modeling, performance and queue theory.

\section{INTRODUCTION}

Generally, man is a mutual being; they co-exist with each other, to deduce mutual benefits. These mutual benefits are deduced from Public infrastructures such as; roads, market places, air-ports, rail ways, banking hall (bank networks), hospitals, public offices, barbering saloon, departure and arrival halls, mobile call centers, recreation centers etc are used together by man. Man deduced comfort from all these facilities and it gives man sense of belonging. Therefore, the usage of these infrastructures by man can leads to total collapse of these infrastructures and man can also; obtain non satisfaction from these infrastructures if not well managed. However, there must be strict measures to ensure customers optimal satisfaction from these infrastructures and to avoid total collapse of these public infrastructures [1]. Satisfaction is obtained from public infrastructure, when customers waiting time, length of queue is reduced and the

Manuscript received April 10, 2014; revised September 15, 2014.

Osahenvemwen O. A. is with the Department of Electrical and Electronic Engineering, Faculty of Engineering and Technology, Ambrose, Alli University, Ekpoma, Edo State, Nigeria (e-mail: osahenvemwenaustin@ymail.com; tel.+2348037273256)

Odiase O. F. is with the Department of Electrical and Electronic Engineering, Faculty of Engineering, University of Benin, Edo State, Nigeria (e-mail: odiase3purpose@gmail.com) quality of services increases. There are always queue of customers waiting to utilize these public facilities at different place and different point in time. Understanding the nature of lines or "queues" and learning how to manage them is one of the most important areas in operations management. Queues are associated with both external (customer-service) and internal production processes, which include staffing, scheduling and inventory levels [2]. Customers arrives public infrastructures in many ways. They can arrive individually or in groups. They can also arrive and then depart because the expected wait time is too long, which is called balking. Other customers may arrive and wait for a while, only to be frustrated and leave, which is called reneging. These are different categories of arrival rate of customers in a system. The customer arrival process on mobile call center or any public infrastructures can be described by interarrival times [3], [4]. These random customer arrivals can be characterized by probability distribution. However, the most common probability distribution used for arrivals rate is the Poisson distribution [1], [5], [6]. The Poisson distribution is a discretedistribution, meaning that only certain numerical values that will come from the distribution. The values that come from the Poisson distribution are whole numbers greater than or equal to zero and it possesses a unique characteristic such as orderliness and memoryless [1]. A value from the Poisson distribution represents a number of customers arriving at a service point, in a particular period of time.

\section{A. The Mobile Call Center Facility}

Therefore, let consider the call center facility designed to support the delivery of mobile communication networks through effective interactive service via telephone communication such as calls and text messages. The call center is designed, with an office space, comprises with multiple workstations manned by agents (network staffs) who place and receive calls [7]. The call center applications include; Tele-marketing, customer service; support new promo, and emergency dispatch etc. Most call centers support both inbound and outbound operations. An inbound operation takes customer initiated calls while an outbound operation places calls to customers. Inbound and outbound calls are often handled by separate teams of agents, though in some call centers inbound and outbound calls are mixed in a process known as blending. Even a moderately sophisticated call center is equipped with advanced computer and telecommunication equipment. An inbound call typically connects from the Public Service Telephone Network (PSTN) to the call center's switch, the Private Branch Exchange (PBX), over a number of owned or leased trunk lines. Subscribers (callers) may initially connect to an 
Interactive Voice Response Unit (IVR) where the subscriber can use their keypad to select options and potentially provide data input to call center system. When subscribers need to speak to an agent, the call is handled by the Automated Call Distributor (ACD) [8]. The ACD routes calls internal to the call center and is responsible for monitoring agent status, collecting data, managing on hold queues, and making potentially complex routing decision. For example, in call centers that employ skills basedrouting; a complex decision process is used to match subscribers and agents based on multiple criteria concerning both the subscribers and the agents. In addition, the mobile communication networks have a call center agent usually have a computer terminal connected into one or more enterprise applications; these are typically classified under the general category of Customer Relationship Management (CRM). In lower volume, less sophisticated call centers in mobile communication, information processing systems are completely separated, but most moderately sophisticated centers use some form of Computer Telephony Integration (CTI). CTI allows information to pass back and forth between the two systems. The call center systems typically have some form of CTI middleware usedto manage the integration of network equipment and computing systems [7].

\section{B. The Call Center Modeling Characteristics}

The telecommunication system comprises of calls arriving at the mobile call center communication equipment, which also includes; the personnel's, software's and machinery. These basic factors are used in modeling in mobile communication networks call center. The entire mobile system is divided into two sections as follows; random variable and deterministic. The deterministic implies that the mode of operation is predictable and it comprises of the mobile communication equipments (machinery), personnel's, and the software's. While the random variables are made up of traffic usage, of the mobile call center. This traffic usage is characterized as random variable, therefore; random distribution is a process in which one or more quantities vary with time in such a way that the instantaneous values of quantities are not determined precisely but are predictable with certain probability [9].

The queue theory involves the evaluation of arrival rate and service time factors in mobile call center shown in Fig. 1.

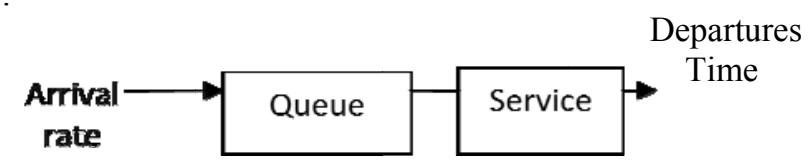

Fig. 1. Simple queuing system.

Queuing theory are used extensively to analyze production and service processes exhibiting random variability in market demand. Queue arise when the demand for service exceeds the capacity, which are often caused by random variation in service times and the times between customer arrivals [3], [10]. Little's law, Little's result, or Little's theorem is perhaps the most widely used formula in queueing theory was published by J. Little in 1961. It is widely applicable, and depends only on weak assumptions about the properties of the queueing system. Queuing theory is used to balance the cost of increased capacity against the increased productivity and service. Also, it is used to analyze waiting time, Queue lengths etc., in this study, queue lengths is referred to as the total number of customers in the system (including both waiting customers and those in service). The service system is characterized by the number of waiting lines, the number of servers, the arrangement of the servers, the arrival rate $(\lambda)$ which is the rate at which requests are generated, Service rate $(\mu)$ is the rate at which requests are serviced, service patterns and the service priority rules are considered [4], [11], [12]. Two types of costs are used todetermine the optimum number of servers in the system, which are service costs and waiting time costs of customers. These costs analysis helps in management, making good economic decision. The trade-off between the increased costs of providing better service andthe decreased of waiting time costs is important parameter that must be deployed [13].

TABLE I: The AVERAge OBTAINED Queue PARAMETERS FROM ONE

\begin{tabular}{|c|c|c|c|c|}
\hline \multicolumn{5}{|c|}{ AGENT OR STAFF } \\
\hline $\mathrm{S} / \mathrm{N}$ & $\begin{array}{l}\text { Mobile } \\
\text { Communicati } \\
\text { on Networks } \\
\text { in Nigeria }\end{array}$ & $\begin{array}{l}\text { Average } \\
\text { Number of } \\
\text { Arrival } \\
\text { Rate } \\
\text { (Busy } \\
\text { Hour) }\end{array}$ & $\begin{array}{l}\text { Average } \\
\text { number of } \\
\text { arrival } \\
\text { subscribers at } \\
\text { one agent } \\
\operatorname{deck}(\lambda)\end{array}$ & $\begin{array}{l}\text { Average } \\
\text { Service } \\
\text { Time } \\
\text { (mins) }(\mu) \\
\text { (At Busy } \\
\text { Hour) }\end{array}$ \\
\hline 1 & MTN & 5610 & 5 & 17 \\
\hline 2 & Globacom & 4071 & 4 & 15 \\
\hline 3 & Airtel (zain) & 2107 & 3 & 10 \\
\hline 4 & Etisatal & 1738 & 3 & 8 \\
\hline
\end{tabular}

\section{Methodology}

This research is focused on effective utilization of public infrastructural usage, case study of mobile call center using queuing models and evaluation of queue parameters analysis. In this research, mobile call centers of MTN, Globacom, Airtel (Zain) and Etisalat mobile communication were considered. Data on arrival calls, service time were obtained for a period of one year. Mathematical analysis, based on queue theory was deployed to analyze the data obtained from the call centers in mobile communication networks in Nigeria. The assumed queue parameters are as followed; Single Channel (one staff), probability distribution is assumed a Poisson Arrival and Exponential Service Time, which is represented by Kendall notation as $(\mathrm{M} / \mathrm{M} / 1)$. The simplest model represents a system that has one server (or possibly a single agent or one staff). The queue theory is based on First-Come, First-Served discipline and it is assumed that the customer arrival rate can be approximated by a Poisson distribution and service time by a negative exponential distribution, or Poisson service rate. The length of queue can be endless, just as the demand for call services is endless.

The formulas deduced form the single-channel model is used to determine the performance parameters which includes;

$L q=$ mean number of customer waiting in queue

$L s=$ mean number of customer in being service

$w=$ the total mean time spent in the system (also called sojourned time) 
$w_{q}=$ mean time a customer spends in the queue $p=$ system utilization

\section{DATA ANALYSIS}

Suppose arriving customers (subscribers) in system has a probability $P$, which is independent of the number of people in the system. If the arriving customer is of type $K$ with probability $P_{K}$, therefore

$$
\begin{aligned}
& \sum_{k=0}^{\infty} P_{K}=1 \\
& L=\sum_{k=0}^{\infty} K P_{K}= \\
& \text { NoteP }_{K}=(1-P) P^{K} \\
& L=\sum_{k=0}^{\infty} K(1-P) P^{K}=(1-P) \sum_{k=0}^{\infty} K P_{K} \\
& (1-P) P \frac{d}{d p} \sum_{k=0}^{\infty} P^{K}=(1-P) P \frac{d}{d p}\left(\frac{1}{1-P}\right) \\
& (1-P) \frac{P}{(1-P)^{2}}=\frac{1}{(1-P)}=\frac{\lambda}{\mu-\lambda}
\end{aligned}
$$

$L=$ the mean number of customers in the system

$L_{q}=$ the mean number of customer in a waiting queue can be determining from the steady state distribution as follows:

$$
\begin{gathered}
L_{Q}=\sum_{k=1}^{\infty}(K-1) P_{K}= \\
\sum_{k=1}^{\infty}(K-1) P_{K}=\sum_{k=1}^{\infty} K P_{K}-\sum_{k=1}^{\infty} P_{K} \\
L-P \\
\frac{\lambda}{\mu-\lambda}-\frac{\lambda}{\mu} \\
N o t e P=\frac{\lambda}{\mu} \\
\frac{\mu \lambda-\lambda(\mu-\lambda)}{\mu(\mu-\lambda)}=\frac{\lambda^{2}}{\mu(\mu-\lambda)}
\end{gathered}
$$

$L_{s}=$ the mean number of customer in service is given as

$$
\begin{gathered}
L_{S}=0 . P_{0}+\sum_{k=1}^{\infty} 1 . W_{K}=1-P_{0}=P=\frac{\lambda}{\mu} \\
P=\frac{\lambda}{\mu}=\text { system utilization }
\end{gathered}
$$

Note that $L=L_{S}+L_{q}$

$$
\begin{gathered}
L=\frac{\lambda}{\mu}+P=\frac{\lambda}{\mu(\mu-\lambda)} \\
L=\frac{\lambda}{(\mu-\lambda)}
\end{gathered}
$$

Recall from little theory that

$$
L=w \lambda
$$

$w=$ the total time spent in the system is referred to as sojourned time

$w_{q}=$ mean time a customer spends in the queue

$w_{s}=$ mean time a customer spends in the service

$w=w_{s}+w_{q}$
From equation

$$
w=\frac{L}{\lambda}=\frac{\lambda}{\mu-\lambda} \cdot \frac{1}{\lambda}=\frac{1}{\mu-\lambda}
$$

$\therefore w_{q}$, using littletheory

$$
\begin{gathered}
L_{q}=w_{q} \lambda \\
w_{q}=\frac{L_{q}}{\lambda}=\frac{\lambda^{2}}{\mu(\mu-\lambda)} \cdot \frac{1}{\lambda}=\frac{\lambda}{\mu(\mu-\lambda)}
\end{gathered}
$$

\begin{tabular}{|c|c|c|c|c|c|c|}
\hline $\begin{array}{l}\mathrm{S} / \\
\mathrm{N}\end{array}$ & $\begin{array}{l}\text { Mobile } \\
\text { networks }\end{array}$ & $\begin{array}{l}\text { The } \\
\text { mean } \\
\text { number } \\
\text { of } \\
\text { customer } \\
\text { in } \\
\text { service } \\
\text { (Ls) }\end{array}$ & $\begin{array}{l}\text { The } \\
\text { mean } \\
\text { number } \\
\text { of } \\
\text { customer } \\
\text { in a } \\
\text { waiting } \\
\text { queue } \\
\text { (Lq) }\end{array}$ & $\begin{array}{l}\text { The } \\
\text { mean } \\
\text { waiting } \\
\text { time of } \\
\text { customer } \\
\mathrm{s} \text { in the } \\
\text { queue } \\
\text { (Wq) }\end{array}$ & $\begin{array}{l}\text { The } \\
\text { mean } \\
\text { waiting } \\
\text { time of } \\
\text { customer } \\
\mathrm{s} \text { in the } \\
\text { system } \\
\text { (W) }\end{array}$ & $\begin{array}{l}\text { system } \\
\text { utilizati } \\
\text { on (p) }\end{array}$ \\
\hline 1 & MTN & 0.416 & 0.123 & 0.025 & 0.083 & 0.294 \\
\hline 2 & Globacom & 0.364 & 0.097 & 0.024 & 0.091 & 0.267 \\
\hline 3 & Airtel & 0.429 & 0.129 & 0.043 & 0.143 & 0.300 \\
\hline 4 & Etisalat & 0.600 & 0.225 & 0.075 & 0.200 & 0.375 \\
\hline
\end{tabular}

The mean amount of time a customer spends in service

\begin{tabular}{|c|c|c|c|c|}
\hline \multirow[t]{2}{*}{$\mathrm{S} / \mathrm{N}$} & \multicolumn{2}{|c|}{$\begin{array}{l}\text { Estimate of queue length } \\
\text { based on number of arrival } \\
\text { subscribers using } \\
\text { parameters }\end{array}$} & \multicolumn{2}{|c|}{$\begin{array}{l}\text { System utilization using MTN } \\
\text { network parameters }\end{array}$} \\
\hline & $\begin{array}{l}\text { Number of } \\
\text { arrival }\end{array}$ & $\begin{array}{l}\text { Estimated } \\
\text { probability of } \\
\text { idle time in } \\
\text { percentage }\end{array}$ & $\begin{array}{l}\text { MTN system } \\
\text { utilization (s) } \\
\text { based on the } \\
\text { number of staff of } \\
\text { agents }\end{array}$ & $\begin{array}{l}\text { system } \\
\text { utilization } \\
\text { in } \\
\text { percentage }\end{array}$ \\
\hline 1 & 0 & $70.6 \%$ & $\mathrm{~S}=1$ & $29.4 \%$ \\
\hline 2 & 1 & $20.8 \%$ & $S=2$ & $14.7 \%$ \\
\hline 3 & 2 & $6.1 \%$ & $S=3$ & $9.8 \%$ \\
\hline 4 & 3 & $1.8 \%$ & $S=4$ & $7.4 \%$ \\
\hline
\end{tabular}
$\left(w_{s}\right)$

$$
w_{s}=\frac{L_{s}}{\lambda}=\frac{\lambda}{\mu} \cdot \frac{1}{\lambda}=\frac{1}{\mu}
$$

\section{RESUlTS AND DiscUSSION}

The mean number of customers in service $\left(L_{s}\right)$ is determined from Equation (13), the mean number of customers in a waiting queue $\left(L_{q}\right)$ is determined from Equation (9), the mean waiting time of customers in the queue $(W q)$ is determined from Equation (17), the mean waiting time of customers in the system $(W)$, is also called sojourned time, which is determined from Equation (15), and system utilization is determined from Equation (11). The resultant outputs deduced from the Equations and corresponding parameters are presented in Table II.

TABLE II: VARIOUS PARAMETERS DEDUCED FROM MOBILE CALL CENTERS IN NiGERIA MOBILE COMMUNICATION NETWORKS

TABLE III: ESTIMATE OF QUEUE LENGTH AND SYSTEM UTILIZATION BASED ON MTN MOBILE NETWORK PARAMETERS

In $\mathrm{M} / \mathrm{M} / 1$ queue models, arrival time cannot be greater than service time. Since there is only one server, the system can tolerate up to $100 \%$ utilization. If arrival rates are more than service rates, then a multi-channel queue system is appropriate. Also, let considered a multi- channels or multi- 
staff system such as $\mathrm{M} / \mathrm{M} / \mathrm{Z}$ and compared with $\mathrm{M} / \mathrm{M} / 1$ performance using the same parameters in Table I, presented in Table IV.

TABLE IV: COMPARISONS BETWEEN M/M/1 AND M/M/Z PARAMETERS

\begin{tabular}{|l|l|l|l|}
\hline $\mathrm{S} / \mathrm{N}$ & Performance Parameters & $\mathbf{M} / \mathbf{M} / \mathbf{1}$ & $\mathbf{M} / \mathbf{M} / \mathbf{Z}$ \\
\hline 1 & $\begin{array}{l}\text { The mean number of customer in } \\
\text { service or being served }(L s)\end{array}$ & 0.416 & 0.00191 \\
\hline 2 & $\begin{array}{l}\text { The mean number of customer in a } \\
\text { waiting queue }(L q)\end{array}$ & 0.123 & 0.00650 \\
\hline 3 & $\begin{array}{l}\text { The mean waiting time of } \\
\text { customers in the queue }(W q)\end{array}$ & 0.025 & 0.00130 \\
\hline 4 & $\begin{array}{l}\text { The mean waiting time of } \\
\text { customers in the system }(W) \text { (also } \\
\text { called sojourn time) }\end{array}$ & 0.083 & 0.00038 \\
\hline
\end{tabular}

The $M / M / Z$ model parameters are based on the assumption of two server or staff in a system.

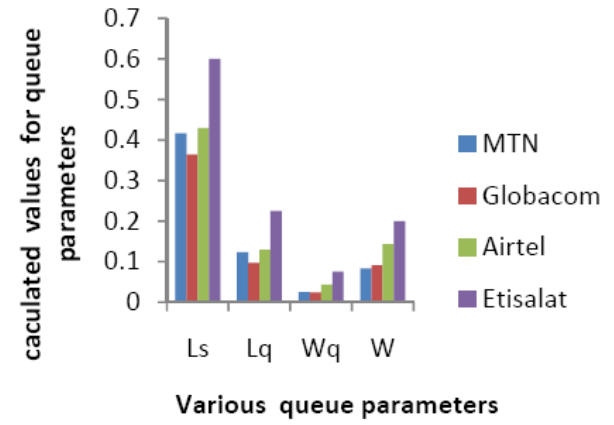

Fig. 2. Plot of queue parameters for different mobile communication networks.

In Fig. 2 shown different levels of average number of customers being served, the length of the queue and average number of customers in the system (waiting and being served) for various mobile networks operators in Nigeria.

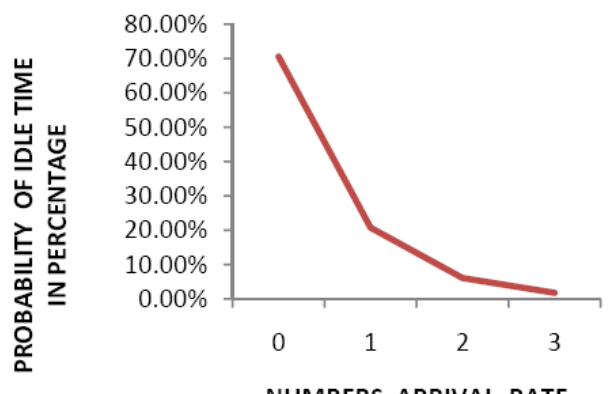

NUMBERS ARRIVAL RATE

Fig. 3. Plot of number of arrival rate againstprobabilityof idle time percentage.

It is observed that the estimated probability of idle time in percentage of the system decreases with the number of arrival rate shown in Fig. 3. In addition, there must be a balance point between arrival rate and probability of idle time, low probability of idle time will lead to decreases in utilization rate and profit losses. Also, high probability of idle time will generate into high waiting time in the system, long queue and low quality of service from the system. Therefore the probability of idle time must be kept within a manageable percentage with equivalent arrival rate. In Fig. 5 show the system utilization based on the number of agents or staff available with given number of arrival rate. It is observed as the number of staff or agents increases with given number of arrival rate the system utilization rate increases. The system utilization must be kept within a certain range to minima cost in the system. It is observed that increase in capacity, such as with too many staff (servers) will leads to under utilization of the system, increases the idleness time. However, if there is little capacity with few servers then the customers may spend much of their time in waiting to be served (see Fig. 4).

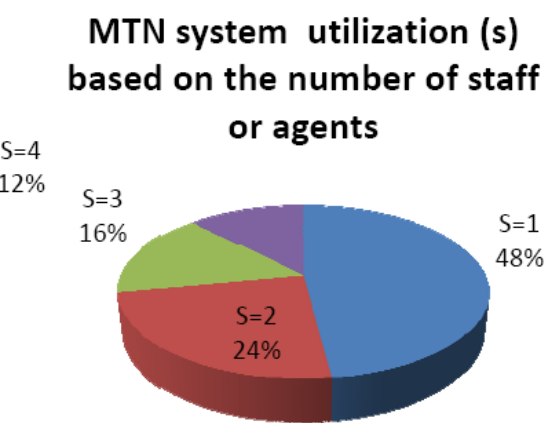

Fig. 4. Systemutilization based on the number of agents or staff against a given number of arrivals.

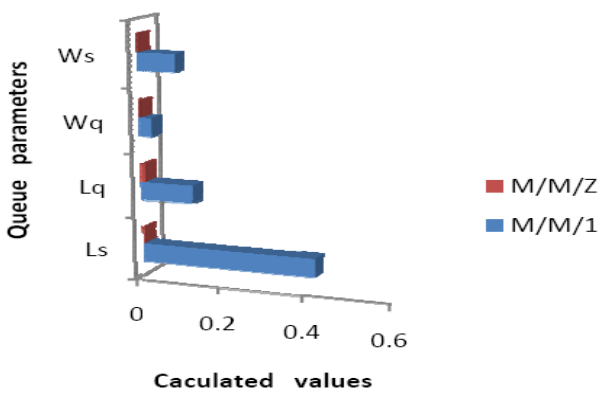

Fig. 5. Thecomparison between single (M/M/1) and multiple (M/M/Z) server or staff.

Fig. 5 show the comparison between deploying single staff and multiple staff, it observed that increases in number of personnel or capacity will reduce the waiting time, length of queue etc, then the costumers satisfaction is increased. The trade-off decision, it is an important parameter deployed by business operators must used to weigh the added cost of providing more rapid service against the inherent cost of waiting due to customers walking away disgusted because of insufficient customer support personnel or long time of waiting.

\section{CONCLUSION}

This paper presentseffective utilization of public infrastructure, case study of mobile call centre in mobile communication networks. Often time, the use of public infrastructure always witnessed queue of customer waiting to be served. This customer queue is analyzed by using queue models parameters to determine the performance of the system. The mobile call centre was considered in this study, it is deployed along side with mobile communication network to provide support service to the entire system. Data were obtained from mobile call centre from Nigeria mobile communication operators for a period of one year. The rate at which call arrival and the service rate at mobile call center are analysis using queue theory to determined queue parameters which include; the mean number of customer in service or being served $(L s)$, the mean number 
of customer in a waiting queue $(L q)$, the mean waiting time of customers in the queue $(W q)$, The mean waiting time of customers in the system (W) (also called sojourn time) and system utilization $(p)$. It is observed that increase in capacity, such as with too many staff (servers) will leads to under utilization of the system, increase in their time in idleness. However, if we have too little capacity with too few servers then customers may spend much of their time in idleness waiting to be served.Increase in the existing service facilities would reduce the customers waiting time; also increase in the level of service increase the cost of operating the services facilities increases the cost of waiting. If the customers queue time is reduced, then the costumer's satisfaction is increased.

\section{REFERENCES}

[1] O. A. Osahenvemwen, F. O. Edeko, and J. O. Emagbetere, "Elusive statistical property of arrival rate and holding time used in mobile communication networks," International Journal of Computer Applications, vol. 59, no. 2, pp. 15-18, USA, 2012.

[2] Queuing Theory and Practice: A source of competitive advantage, [Online]. Available: http:// www. Isixsigma com/industries/retail/ queuing-theory- and -practice-source-competitiveadvantage/

[3] J. Sztrik, "Queueing theory and its applications," in Proc. the 8th International Conference on Applied Informatics Eger, Hungary, vol. 1. pp. 9-30, 2010.

[4] T. Sheikh, S. K. Singh, and A. K.Kashyap, "Application of queuing theory for the improvement of bank service," International Journal of Advanced Computational Engineering and Networking, vol. 1, no. 4 2010.

[5] J. M. G. Smith, "Properties and performance modeling of finite buffer M/G/1/K networks," Computers and Operations Research, vol. 2, 2010.

[6] Teletraffic Engineering International Telecommunication union. [Online]. Available: http://www.itu.int

[7] S. S. Ray and P. Sahoo, "Monitoring of network traffic based on queuing theory," ARPN Journal of Science and Technology, vol. 1, no. $1,2011$.

[8] S. Sanjay, Computer Networks, $1^{\text {st }}$ edition, pp. 621-629, 2010.

[9] E. O. Oyatoye, "Application of queueing theory to port congestion problem in Nigeria," European Journal of Business and Management, vol. 3 , no. 8,2011 .
[10] J. Abate and W. Whitt, "Calculating time dependent performance measures for the $\mathrm{M} / \mathrm{M} / 1$ Queue," IEEE Transaction on Communications, vol. 37, no. 10, 1989.

[11] L. S. Kuravsky and S. B. Malykh, "Application of Markov models for analysis of development of psychological characteristics," Australian Journal of Educational \& Developmental Psychology, vol. 4, pp. 2940, 2004.

[12] L. Sharma, Operation Research Theory and Application, $4^{\text {th }}$ edition, Macmillan publishers India Ltd, pp. 582-631, 2010.

[13] M. M. Kembe, E. S. Onah, and S. Iorkegh, "A study of waiting and service costs of a multi-server queuing model in a specialist hospital," International Journal of Scientific and Technology Research, vol. 1, pp. 18-23, 2012.

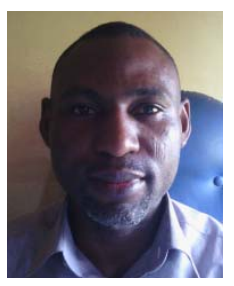

Osahenvemwen O. A. was born in 1975, at Benin City, Edo State, Nigeria. He is a doctor of Philosophy (Ph.D) in telecommunication specialized in telegraphic obtained in 2014 , he received his master degree in electronic and telecommunication in 2005 both at University of Benin, he received his bachelor degree in engineering electrical and electronic Ambrose Alli University and Health Safety and Environmental Officer (HSE component SPDC Accredited) both in 2003. He work interests include: knowledge of both land line and mobile communication system, expect in traffic analysis (teletraffic) and performance in mobile communication networks, knowledgeable in LAN protocol, WAN protocol and TCP/IP suit, installation and maintenance of PABX intercom system for institutions. He is good at computer knowledge in MATLAB software and java program. $\mathrm{He}$ as a senior lecturer position, with Ambrose Alli University, Ekpoma till day. He is good at academic research works, above 30 published journals in telecommunication field. He is member of professional's bodies such as Nigeria Society of Engineers (NSE) with Reg. No 20418 and the Council of the Regulation of Engineering in Nigeria (COREN) with reg. No: R20,800.

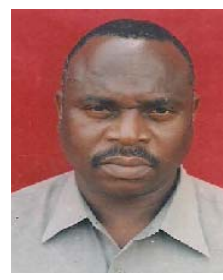

Odiase O. Friday was born in Edo State, Nigeria. $\mathrm{He}$ received his degree (B.Eng) in electrical engineering from Bayero University kano, Nigeria in 1992. He received his master degrees (M.Eng) in electronics/telecommunication and power/machines in 1997 and 2009, and he received his Ph.D in power and machines. He is currently a lecturer with the Department of Electrical/Electronic Engineering, Faculty of Engineering, and University of Benin. His research area is in electrical power loss minimization in electrical distribution network. 